\title{
Banco Internacional de Objetos Educacionais: Repositório Digital para o uso da Informática na Educação
}

\author{
Title: Educational Objects International Base: Digital Repository for using Informatics in Education. \\ Profa.Paloma Alinne Alves Rodrigues \\ Universidade Federal do ABC(UFABC) \\ Centro de Ciências Naturais e Humanas (CCNH) \\ palomaraap@gmail.com \\ Profa.Dra.Elisa Tomoe Moriya Schlünzen \\ Universidade Estadual Paulista (FCT/UNESP) \\ Departamento de Estatística \\ elisa@fct.unesp.br
}

Prof.Dr.Klaus Schlünzen Junior

Universidade Estadual Paulista (FCT/UNESP)

Departamento de Estatística

klaus@fct.unesp.br

\author{
Profa.Dra.Maria Inês Ribas Rodrigues \\ Universidade Federal do ABC (UFABC) \\ Centro de Ciências Naturais e Humanas (CCNH) \\ mariainesribas@gmail.com
}

\begin{abstract}
Resumo O presente artigo tem o intuito de apresentar o repositório educacional "Banco Internacional de Objetos Educacionais (BIOE), que é uma das iniciativas do Ministério da Educação (MEC) do Brasil em parceria com universidades públicas e federais, além de instituições internacionais, cujo objetivo principal é propiciar, aos professores, recursos educacionais para serem utilizados em sala de aula. Além disso, deseja-se abordar o caminhar metodológico adotado por uma das pesquisadoras e autora deste trabalho, para pesquisar, selecionar e catalogar os recursos educacionais de Física que se encontram disponíveis neste repositório. Finalizando, serão apresentados os resultados quantitativos relacionados aos recursos educacionais catalogados, bem como as iniciativas relacionadas à formação de professores para o uso deste repositório por meio de cursos na modalidade a Distância, além das pesquisas de mestrado e doutorado desenvolvidas na Faculdade de Ciências e Tecnologia (FCT/UNESP) e na Universidade Federal do $A B C(U F A B C)$.
\end{abstract}

Palavras-Chave: Tecnologia, Educação, Repositório Educacional, Formação de Professores, Banco Internacional de Objetos Educacionais (BIOE), Objetos Educacionais

\begin{abstract}
This article intends to present the educational repository "The International Educational Objects Bank" (BIOE), an iniciative of the Brazilian Education Ministry (MEC) in partnership with public and federal universities in addition to international institutions, its principal object is to make educational resources for classroom use available to teachers. Furthermore, we want to address the methodological course chosen by one of the researchers, the author of this article, in researching, choosing and cataloging the educational resources for Physics made available through the repository. In conclusion quantitative results related to the cataloged educational resources will be presented, iniciatives related to the training of teachers in the use of the repository through the use of Distance learning modules, as well as the research carried out by Master's and Doctorate courses in the Science and Technology Faculty (FCT/UNESP) and the Federal University of $A B C(U F A B C)$
\end{abstract}

Keywords: Technology, Education ,Educational Repository, Training of teachers International Educational Objects Base (BIOE), Educational Objects 


\section{Introdução}

A tecnologia, cada vez mais presente em nosso cotidiano, tem propiciado ao ser humano inúmeras facilidades que tornam sua vida mais prática e interessante; seja por meio da realização de atividades corriqueiras ou até mesmo relacionadas ao lazer. Sob este enfoque, destacamos o uso frequente das mídias, principalmente entre os jovens, devido a enorme facilidade de comunicação e acesso à internet por meio de computadores e tablets. Diante deste contexto, seria natural que a escola, em especial o professor, inserisse as mídias em sala de aula, a fim de articular o seu uso aos conteúdos curriculares, com o objetivo de instigar e envolver o aluno na construção de novos conhecimentos.

Contudo, o que se presencia no dia a dia da escola são os argumentos dos professores de que a tecnologia está ainda muito distante do ambiente de ensino, principalmente em países em condições sócio-econômicas e políticas desfavorecidas. Longe disso, este fundamento não se sustenta mediante os constantes avanços tecnológicos e a uma sociedade cada vez mais integrada em rede, com a predominância de um forte movimento de integração de mídias. É importante lembrar, como o maior exemplo, a disseminação de telefones celulares nas camadas mais populares.

Nessa mesma direção, constata-se o cenário desmotivador entre alunos e professores no contexto escolar. Uma situação que pode ser revertida, de forma significativa, mediante o uso das tecnologias como uma potencial ferramenta para auxiliar na relação escola-aluno.

Se por um lado ao utilizar as tecnologias fora da realidade escolar, o jovem sente-se instigado a descobrir novos mundos e ainda relatar descobertas; comunicar-se com os colegas; realizar leituras e conhecer, virtualmente, lugares e pessoas. Por outro, frente à rotina da sala de aula, como aluno, sente-se desmotivado, argumentando ainda dificuldades em compreender os conteúdos curriculares, principalmente em disciplinas que fazem uso de conceitos abstratos, tais como a Química; Matemática e em especial a Física.

Vale lembrar que a incorporação das Tecnologias de Informação e Comunicação (TIC), em sala de aula, não é em si mesma um fator de transformação e inovação no processo de ensino e aprendizagem, pois os resultados das pesquisas da área de ensino tornam evidente a prática inadequada do professor. Assim, destaca-se a importância de rever o processo formativo do professorado para que haja uma mudança no uso das TIC em contextos escolares para um aprendizado condizente aos novos tempos.
Através de estudos realizados com relação ao uso das tecnologias na esfera pedagógica [1;2;3 e 4], tornou-se evidente a necessidade de formar os professores para a implementação deste recurso no contexto escolar.

Neste sentido, vale lembrar que, ao inserir as tecnologias em suas aulas, o professor assume um papel de extrema relevância, pois de acordo com Carvalho [5], as "[...] pesquisas que estudam a sala de aula têm mostrado como é fundamental o papel do professor no desempenho dos alunos [..] [5]".

Além da necessidade de uma formação de qualidade, na qual o professor desenvolva as habilidades da reflexão sobre a prática, como apontado em Rodrigues e Perrenoud [6;7], é imprescindível que este profissional conheça diferentes recursos para serem implementados em sala de aula.

Desta forma, ao refletir sobre sua prática e procurar modificá-la, o professor terá ao seu dispor também as ferramentas tecnológicas, que podem contribuir de forma significativa para o desenvolvimento do aluno, além de potencializar o processo de ensino e aprendizagem.

Mediante esses pressupostos, o presente artigo possui dois objetivos. O primeiro é apresentar uma das iniciativas do Ministério da Educação (MEC), em parceria com universidades brasileiras e instituições internacionais, em propiciar aos professores diferentes tipos de Objetos Educacionais (OE), disponibilizados para serem articulados ao plano de aula, por meio de repositórios digitais educacionais.

O segundo objetivo será apresentar o caminhar metodológico, adotado por uma das pesquisadoras e autora deste trabalho, para pesquisar, selecionar e catalogar OE de Física que se encontram disponíveis neste repositório. Para finalizar, serão apresentados os resultados quantitativos relacionados ao período de pesquisa, seleção e catalogação desses OE, assim como algumas iniciativas adotadas para formar professores para o seu uso. Desse modo, para auxiliar o leitor na compreensão do texto, inicialmente será apresentado o conceito de repositório, assim como as suas principais características.

\section{Repositórios}

Mediante o conceito de filosofia aberta, conhecida também como Open Acess, qualquer individuo independente da sua localização pode acessar materiais acadêmicos ou científicos, sem nenhum tipo de restrição ou custo. Para tanto, este acesso pode ser realizado de duas manei- 
ras: por meio de revistas eletrônicas ou repositórios digitais.

Assim, compreende-se que os repositórios digitais são constituídos por um sistema de informação que permite armazenar, organizar, e compartilhar diferentes tipos de materiais, a fim de proporcionar um acesso transparente e democrático[16].

Além do compartilhamento de materiais acadêmicos e científicos, o Brasil em consonância com as tendências internacionais, desenvolveu repositórios voltados para o contexto de ensino e aprendizagem. Se por um lado proporcionam aos alunos autonomia para acessar os conteúdos escolares independente da sua localização geográfica, por outro possibilitam aos professores uma nova ferramenta para ser articulada ao plano de aula. Desse modo, os repositórios educacionais, são definidos como um local, que armazena e organiza conteúdos digitais pedagógicos para que possam ser utilizados em sala de aula, por meio da articulação ao plano de aula do professor.

Nos últimos anos, diferentes tipos de repositórios educacionais foram criados para os profissionais da área da Educação. Estes repositórios configuram-se como subsídios para incorporar de forma significativa as tecnologias no contexto de ensino e aprendizagem. Dentre os mais interessantes podemos destacar duas iniciativas brasileiras e uma de cunho internacional:

- LabVirt (Laboratório Virtual da Universidade de São Paulo - USP): disponibiliza para professores das disciplinas de Física e Química diversas simulações e animações.

- Portal do Professor:propiciar para professores de todas as modalidades de ensino diferentes materiais, como por exemplo:sugestões de aula, conteúdos multimídia, cursos, entre outros.

- Merlot (Multimedia Educational Repository for Learning and On - line Teaching): é um repositório que tem como principais usuários professores do ensino superior.Por meio dele os professores compartilham aulas e atividades. Sendo este um dos repositórios mais acessados do mundo.

Contudo, como citado anteriormente, um dos objetivos do presente artigo é apresentar uma das iniciativas do governo brasileiro em propiciar aos professores um repositório educacional que disponibiliza diferentes tipos de recursos educacionais, conhecidos como Objetos Educacionais (OE). Para tanto, este assunto será abordado no tópico a seguir.

\subsection{Repositório educacional: "Banco Interna- cional de Objetos Educacionais (BIOE)"}

Com o intuito de aprimorar a inserção das mídias no contexto educacional e propiciar aos professores recursos pedagógicos de qualidade para serem articulados ao plano de aula, em 2008 foi desenvolvido pelo Ministério da Educação (MEC) e outras instituições internacionais, o repositório educacional "Banco Internacional de Objetos Educacionais (BIOE)” [11], cuja página inicial é ilustrada pela Figura 1.

Este repositório educacional disponibiliza recursos pedagógicos compreendidos como Objetos Educacionais (OE) que são definidos "[...]como qualquer recurso, suplementar ao processo de ensino e aprendizagem, que pode ser reusado para apoiar a aprendizagem" [12]. Os OE possuem o intuito de aprimorar o processo de ensino, ou seja, auxiliar o professor no desenvolvimento das suas atividades com o intuito de propiciar o desenvolvimento de uma aprendizagem significativa para os alunos.

Os OE, que se encontram disponíveis no BIOE, possuem diferentes formatos como: simulação, animação, experimentos práticos, vídeos, imagens, hipertextos, softwares educacionais. Devido a essa diversidade de materiais, o professor tem a oportunidade de criar diferentes estratégias pedagógicas, a fim de potencializar o processo de ensino e aprendizagem. Além disso, os $\mathrm{OE}$ estão disponíveis de forma gratuita e em três idiomas, sendo eles:português, espanhol e inglês. 
Desse modo, para propiciar a esses profissionais diferentes recursos, por meio do BIOE, de forma a serem implementados no contexto escolar, o MEC contou com a participação de equipes de alunos de graduação de universidades públicas estaduais e federais. Esta equipe foi responsável por pesquisar, selecionar e catalogar os $\mathrm{OE}$.

Para tanto, com o intuito de contemplar o segundo objetivo deste artigo, no próximo tópico será apresentado o processo de parceria com a Faculdade de Ciências Tecnologia (FCT/UNESP), bem como a metodologia utilizada, por uma das pesquisadoras desta equipe, uma das autoras deste trabalho, para pesquisar, selecionar e catalogar os OE relacionados ao conteúdo de Física. É importante lembrar que o objetivo principal era disponibilizar conteúdos de qualidade aos professores da rede pública.

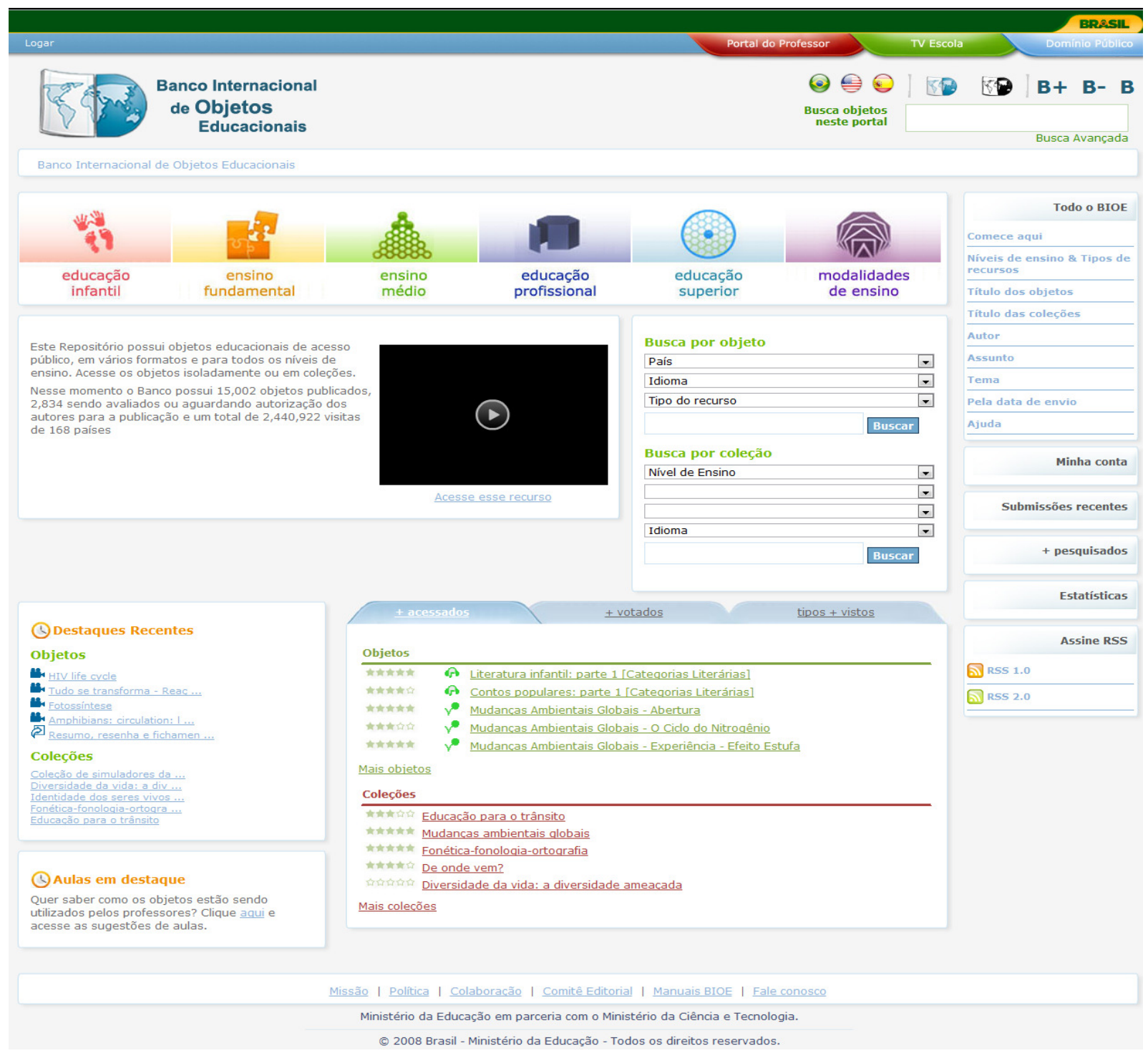

Figura 1:Tela inicial do Banco Internacional de Objetos Educacionais (BIOE)

\section{A parceria com as Universidades}

Com o intuito de estabelecer uma parceria com as universidades federais e estaduais para atuarem no projeto do repositório educacional do BIOE, o MEC por meio de um edital, apresentou e convidou essas instituições. Nes- 
te mesmo edital, o MEC evidenciou que este projeto seria desenvolvido apenas por alunos de graduação, e que cada universidade seria responsável por selecionar alunos de diferentes cursos. Desse modo, ao analisar este edital a equipe da FCT/UNESP, interessada em contribuir com a formação dos alunos do curso de licenciatura, desejou participar do projeto, e no decorrer do período de seleção, entre as instituições inscritas, ela foi contemplada, tendo assim a sua parceria estabelecida com o MEC.

Desse modo, tendo em vista a necessidade de garantir a eficiência dos trabalhos que seriam desenvolvidos por esses alunos, cada instituição parceira possuía um coordenador geral, que era o responsável por selecionar os alunos dos cursos de graduação, bem como para coordenar as atividades da equipe.

Em função disso, para selecionar esses alunos diversas reuniões foram realizadas, pelo coordenador geral. Nessas oportunidades o coordenador pode acompanhar o caminhar do aluno no seu curso de formação, assim como o seu compromisso para com o projeto, sendo que a equipe tinha a responsabilidade de catalogar $800 \mathrm{OE}$ até o ano final de vigência do projeto.

Assim, ao término deste período de seleção a equipe da FCT/UNESP foi composta por 16 alunos de graduação dentre os cursos de: Física, Matemática, Química, Engenharia Ambiental, Geografia e Educação Especial. E para potencializar os trabalhos e verificar as atividades realizadas pela equipe, semanalmente eram realizados encontros na universidade, onde todos os alunos envolvidos tinham a oportunidade de expressar suas dúvidas, dificuldades e os resultados alcançados até aquele momento.

Além disso, para otimizar a relação entre as subequipes, cada uma delas possuía um coordenador de área específica, que tinha a responsabilidade de analisar as atividades desenvolvidas pelo aluno de graduação, além de auxiliá-lo com possíveis dúvidas relacionadas a conceitos específicos da sua área de formação. Diante disso, destaca-se que cada aluno desta subequipe possuía autonomia para estabelecer a sua metodologia de busca por esses recursos educacionais. Para tanto, a seguir serão delineados os procedimentos metodológicos adotados por uma das integrantes da subequipe de Física, bem como as estratégias utilizadas pelo MEC para garantir a publicação dos recursos no repositório do BIOE durante o período de pesquisa, seleção e catalogação desses materiais.

\subsection{Processo de Pesquisa, Seleção e Cata- logação de OE de Física}

\subsubsection{Pesquisa}

Pensando em favorecer e potencializar o processo de localização dos OE, o MEC delimitou e informou as regiões brasileiras e internacionais que poderiam ser pesquisadas por cada uma das equipe das universidades, conforme apresenta a Tabela 1.

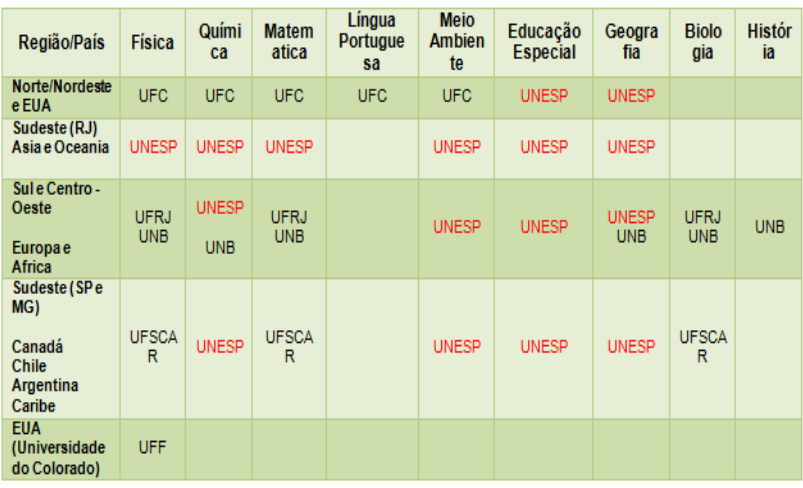

Tabela 1: Áreas de Abrangência

Além disso, para favorecer e garantir a publicação dos OE que seriam localizados, o MEC elaborou e enviou para cada equipe, um documento jurídico denominado "Termo de Cessão de Direito Autoral". Este documento é conhecido como um contrato entre os pares, que visava garantir a autorização do autor diante da publicação ou adaptação da sua obra.

Vale ressaltar que no período de buscas localizou-se obras que não necessitavam da autorização do autor. Dentre estas pode-se citar as de Domínio Público e outras relacionadas na Lei $\mathrm{N}^{\circ} 9610$ art. $8^{\circ}$. As demais obras, que foram localizadas, selecionadas e catalogadas, somente fariam parte do BIOE mediante autorização do autor. Assim, a partir da definição da área de pesquisa, cada integrante possuía autonomia para localizar os recursos educacionais, tanto no Brasil, como no exterior:

\section{- Pesquisas no Brasil:}

Em função da necessidade de localizar OE com qualidade pedagógica, buscou-se em um primeiro momento 
visitar os sites das universidades brasileiras, que possuíam o curso de licenciatura e bacharelado em Física. No decorrer deste processo, verificou-se que algumas instituições da região do estado do Espírito Santo não disponibilizavam recursos digitais relacionados ao ensino desta área de conhecimento. Por outro lado, no estado de São Paulo localizou-se inúmeros materiais.

Vale ressaltar que, neste período, tornou-se possível estabelecer parcerias com empresas privadas, que elaboravam softwares para serem comercializados, assim como com professores da rede pública de ensino, que elaboravam os seus próprios materiais pedagógicos, em formato de vídeos e experimentos práticos e os disponibilizavam em sites particulares e blogs na web. No entanto, é importante evidenciar que, muitos autores brasileiros, em um primeiro momento, salientavam o desejo em contribuir com o repositório. Contudo, ao tomarem conhecimento de que o projeto não possuía finalidade lucrativa, recusavam a publicação dos seus materiais. Mesmo mediante desta dificuldade, localizaram-se $110 \mathrm{OE}$ relacionados aos conteúdos de Física.

\section{- Pesquisas no Exterior}

As pesquisas no exterior, assim como no Brasil, concentram-se em sites de instituições de ensino superior. Contudo, como tinha-se a possibilidade e autonomia para pesquisar em diferentes países, foi possível obter recursos de países, como Argentina, Espanha, Colômbia, Peru, Uruguai, México e Bahrain.

Diferente de alguns autores brasileiros, os autores estrangeiros demonstraram um real interesse em contribuir com o projeto, mesmo este não possuindo finalidade lucrativa. Dessa forma, as pesquisas no exterior oportunizaram localizar 593 OE, que abordavam os conteúdos de: Cinemática, Eletricidade, Ótica, Ondas e Eletromagnetismo.

No próximo tópico será delineado o processo de seleção e catalogação desses recursos.

\subsubsection{Seleção}

Ao término do processo de pesquisa, iniciou-se o processo de seleção e avaliação dos OE. Sendo que, o processo de pesquisa apenas permitiu identificar os recursos disponíveis na web. No entanto, o processo de seleção possui um caráter mais intrínseco, o de verificar a qualidade pedagógica dos recursos localizados. Neste processo utilizou-se como subsídio a Lei de Diretrizes e Bases da Educação Brasileira (LDB) e os Parâmetros Curriculares Nacionais (PCN) de Física, tendo em vista a necessidade de examinar se os recursos selecionados estavam em acordo com os objetivos delineados para Educação Brasileira.

Por meio desses materiais, selecionou-se e avaliou-se, os seguintes OE relacionados ao ensino de Física:

- Vídeos: definidos como um recurso tecnológico de processamento de sinais eletrônicos, analógicos ou digitais, que representam imagens em movimento[14].

- Animação: operação da informação digital e produzida a partir de algoritmos matemáticos constituídos de regras especificadas pelo programador [14].

- Simulação: técnica de estudar o comportamento e reações de um determinado sistema através de modelos que imitam, na totalidade ou em parte, as propriedades e comportamentos deste sistema em uma escala menor, permitindo sua manipulação e estudo detalhado[14].

- Experimento Prático: atividade para comprovar as hipóteses ou teorias levantadas, as quais podem então ser chamadas de leis e consideradas verdadeiras [15].

Neste período de análise, cada Universidade possuía a responsabilidade de selecionar e avaliar os objetos do ponto de vista conceitual e pedagógico. Esta responsabilidade proporcionou aos alunos de graduação, bolsistas do projeto, a oportunidade de construir novos saberes relacionados a sua área de formação específica.

Entre os critérios de análise desses OE, cabe destacar:

- o rigor científico do $\boldsymbol{O E}$ : exigia-se o domínio sobre o conteúdo específico da sua área de formação, possibilitando ao aluno, condições de verificar, de forma minuciosa, os conceitos pedagógicos envolvidos no objeto. Destaca-se que, neste momento era fundamental lançar um olhar crítico sobre o OE;

- qualidade pedagógica: analisar se o objeto poderia propiciar uma aprendizagem significativa e se estava em acordo com os PCN;

- a multidisciplinaridade: devido a possibilidade implementação do OE em outras disciplinas do currículo escolar, recomendou-se a busca por novas informações visando construir diferentes conhecimentos sobre outras áreas.

\subsubsection{Catalogação}

Com relação à catalogação, cabe destacar que a sua definição significa "registro em catálogo, inventário e 
classificação" [13]. Desse modo, nos diferentes tipos de repositórios, o processo de catalogação permite descrever as principais informações sobre o material a ser catalogado, neste caso as informações do OE. Destaca-se que a catalogação adequada traz diversos benefícios, como por exemplo: a reusabilidade; a interoperabilidade; e a durabilidade dos materiais. [14]

A partir disso, é fundamental que cada repositório digital defina seu conjunto de "metadados" que permite descrever as características relevantes do material selecionado. Sendo que, os "metadados são compreendidos como um conjunto de palavras ou sentenças (elementos) que resumem e descrevem o conteúdo de um recurso digital, fornecendo informações sobre a acessibilidade, organização e relacionamento entre os dados" [14]. Assim, por meio desta descrição o objeto será inserido em uma área dentro do repositório digital e, por sua vez, facilmente localizado por meio dos mecanismos de busca do próprio repositório.

É importante ressaltar, que no processo de catalogação dos OE de Física foram descritas as seguintes informações: título, autor, idioma, país, endereço eletrônico, data de publicação, nível de ensino, componente curricular, tipo, tema, modalidade, descrição do recurso, objetivo, pré-requisito do recurso, palavras-chave, publicação associada, observação, arquivo inicial para execução, direito autoral e licença.

Assim, ao término deste processo, o OE era redirecionado para a área do Comitê de Avaliadores, sendo este um grupo especializado e constituído por professores e pesquisadores de universidade públicas do país. Segundo Afonso [16], a finalidade deste comitê é "garantir a qualidade e a pertinência do recurso, adequando-o ao nível de ensino correto."

Cabe salientar, que o Comitê era composto por professores de universidades. Desse modo, não mantinham um contato intrínseco com o atual contexto da escola pública brasileira. Devido a isso, em determinados momentos da avaliação dos $\mathrm{OE}$, houve divergências quanto ao parecer das avaliações proferidas por esse comitê. No entanto, esta situação vivenciada serviu em muitos momentos para enriquecer o processo de seleção e análise dos OE e contribuir para o aprimoramento ou para novas orientações de seu uso nos ambientes de aprendizagem.

\section{Resultados}

\subsection{Resultados quantitativos relacionados ao processo de pesquisa, seleção, catalogação dos OE de Física}

No decorrer do projeto tornou-se possível localizar, selecionar e catalogar uma quantidade significativa de OE. Desse modo, no Brasil, nas de regiões de São Paulo e Espírito Santo, localizou-se um total de 110 diferentes tipos de $\mathrm{OE}^{1}$. No entanto, após a seleção e avaliação desses OE, verificou-se que 64 possuíam os critérios estabelecidos pelo MEC, como demonstra a Tabela 2.

Tabela 2: Quantidade de OE no Brasil

\begin{tabular}{|c|c|c|c|c|}
\hline $\begin{array}{c}\text { OE } \\
\text { Localizados } \\
\text { no Brasil }\end{array}$ & Avaliados & Selecionados & Catalogados & Rejeitados \\
\hline 110 & 110 & 64 & 64 & 46 \\
\hline
\end{tabular}

As pesquisas no exterior permitiram localizar 593 OE, como demonstra a Tabela 3. Destaca-se que esses OE eram de diferentes continentes como: América, Europa, Ásia e África. Em virtude da indisponibilidade de tempo, no primeiro ano do projeto avaliou-se $214 \mathrm{OE}$ de Física $^{2}$. Os demais, correspondendo a $379 \mathrm{OE}$, foram avaliados nos anos subsequentes. Desse montante, 89 foram catalogados e publicados, como mostra a Tabela 3. Esses OE eram procedentes de países como: Argentina, Espanha, Colômbia, Peru, Uruguai e México.

\begin{tabular}{|c|c|c|c|c|}
\hline $\begin{array}{c}\text { OE } \\
\text { Localizados } \\
\text { no exterior }\end{array}$ & Avaliados & Selecionados & Catalogados & Rejeitados \\
\hline 593 & 214 & 150 & 89 & 64 \\
\hline
\end{tabular}

Tabela 3: Quantidade de OE do exterior

No primeiro ano de vigência do projeto a equipe de Física, era composta por três alunos que catalogaram 306 $\mathrm{OE}$, sendo que 153 correspondem aos OE catalogados e publicados por uma das autoras deste trabalho. Diante do exposto, deseja-se salientar que a responsabilidade inicial da equipe geral da FCT/UNESP era catalogar 800 recursos educacionais das diversas áreas do conhecimento. No entanto, devido à parceria estabelecida com os autores, que permitiram a publicação dos seus materiais, tornou-se

\footnotetext{
${ }^{1}$ Esta quantidade corresponde ao primeiro ano do projeto, sendo este 2008.

${ }^{2}$ Esta quantidade corresponde ao primeiro ano do projeto, sendo este 2008.
} 
possível superar este valor, e assim foram catalogados $1.250 \mathrm{OE}[17]$.

\subsection{Resultados qualitativos diante da participa- ção da equipe geral neste projeto}

Considerando que o repositório educacional do BIOE é uma ferramenta pedagógica que proporciona subsídios para os professores da rede pública trabalharem de forma contextualizada e significativa no processo de ensino e aprendizagem, tendo em vista a articulação dos OE ao seu plano de aula, identificou-se a necessidade de estabelecer ações de formação de professores para o seu uso.

A partir desta reflexão, as atividades da equipe da FCT/UNESP durante a sua participação neste projeto, também foram na direção de compartilhar com os profissionais da área da Educação, em especial os professores, estratégias para usar esses OE no contexto escolar.

Para isso, ofereceu-se oficinas em eventos científicos e em escolas da rede pública, a fim de compartilhar com esses profissionais estratégias para implementar os recursos em sala de aula. Destaca-se que nesses eventos era ampla e significativa a busca de profissionais por essas oficinas. Além disso, pode-se salientar que o público dessas oficinas era composto por professores da rede pública e privada, do ensino superior, de universidades públicas e privadas, e de gestores de instituições de ensino. Todos esses profissionais argumentavam o interesse em construir novos conhecimentos para articular de forma significativa as tecnologias ao contexto educacional. Por outro lado, diversos professores salientavam que não estavam cientes desta iniciativa do MEC, pois ela não era divulgada em suas instituições de ensino [4;17].

Desse modo, em uma dessas oficinas ${ }^{1}$, buscou-se verificar a percepção dos professores com relação a importância do OE para as suas aulas. Nessa oportunidade, como instrumento de coleta de dados utilizou-se questionários com questões fechadas. Assim, ao analisar uma das questões relacionadas à importância dos $\mathrm{OE}$ para as aulas desses professores, verificou-se que esses OE poderiam propiciar subsídios para que o professor elabore novas estratégias pedagógicas e assim possa aprimorar a sua prática em sala de aula, conforme resultados apresentados na Figura 2 [4] .

\section{Importância dos recursos do BIOE para a aula}

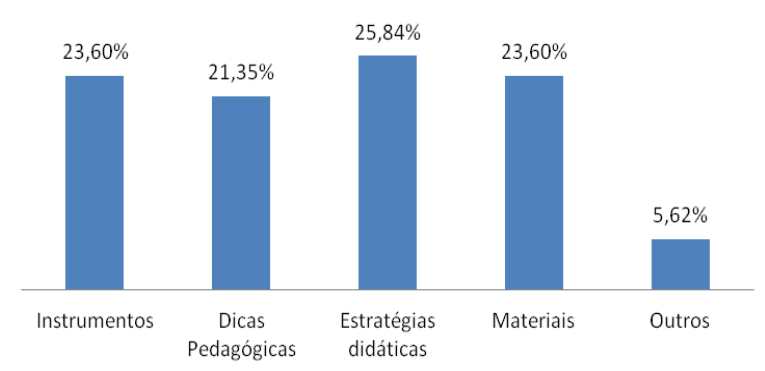

Figura 2:Perspectiva de um grupo de professores com relação aos OE

Além dessas oficinas, a equipe da FCT/UNESP busca divulgar o repositório educacional do BIOE por meio de curso na modalidade de Educação a Distância (EaD) denominado "Tecnologia Assistiva, Projetos e Acessibilidade:Promovendo a Inclusão". Este curso já ofereceu quatro edições e tem caráter de aperfeiçoamento, que beneficiou mais de 1.000 professores da rede pública de todo o Brasil. O curso possui como um dos seus objetivos proporcionar a esses profissionais, subsídios para seu trabalho docente por meio do uso das tecnologias, de forma inclusiva no ensino regular.

Desse modo, um dos conteúdos pedagógicos do curso está relacionado ao repositório educacional do BIOE, onde os professores são convidados a elaborar um projeto utilizando os diferentes tipos de OE para ser desenvolvido com todos os alunos da sala de aula

No início de 2011 a equipe da FCT/UNESP ofereceu, na modalidade EaD, um curso de extensão denominado "Portal do Professor visando práticas inclusivas na sala de aula". Este curso teve a participação de professores da rede pública de ensino do Estado de São Paulo, e sua finalidade foi propiciar subsídios ao professor para articular o uso dos OE ao contexto escolar. Neste curso, os professores eram convidados a conhecer os planos de aula disponíveis no Portal do Professor que utilizam diferentes tipos de $\mathrm{OE}$ e que possuíam estratégias inclusivas. Ao conhecer esses planos, os professores eram convidados a adaptá-los, de acordo com a sua realidade, para serem aplicados com os seus alunos.

Diante desta aplicação, o professor tinha a opção de registrar suas ações por vídeos ou fotografias. Desta forma, foi possível ter um feedback da atuação do professor em sala de aula, mediante da articulação dos OE aos conteúdos curriculares. Por meio da análise dos vídeos observou-se mudanças relacionadas a fatores comportamentais, como a diminuição da indisciplina, o envolvimento intenso dos alunos com as atividades contextualizadas, a satisfação dos professores ao compreender a potencialidade dos alunos usando os OE e como eles podem auxiliá-los em sua prática pedagógica.

Além desses cursos, com o intuito de contribuir com a comunidade científica e educacional, pesquisas de mestrado e doutorado estão sendo desenvolvidas na FCT/UNESP e na Universidade Federal do ABC (U- 
FABC) tendo como principal objetivo analisar a contribuição desses $\mathrm{OE}$ para o processo de ensino e aprendizagem, assim como analisar a formação dos professores para o uso desses recursos

\section{Conclusões}

A internet disponibiliza diferentes tipos de materiais que podem ser utilizados a fim de alcançar inúmeros objetivos, como transmitir informação, lazer, proporcionar novos conhecimentos. Neste sentido, ao abordar o contexto educacional é imprescindível que o professor selecione recursos que possibilitem a construção de novos saberes e que possam propiciar ao aluno uma aprendizagem significativa.

Neste contexto, destaca-se o papel do repositório educacional do BIOE que auxilia o professor no acesso e uso de materiais de qualidade, tendo em vista tantas possibilidades que a internet oferece. Assim, salienta-se que para disponibilizar esses materiais de qualidade, o seu processo de pesquisa, seleção e catalogação é de suma importância.

A criação do repositório educacional do BIOE é uma importante iniciativa do Ministério da Educação para oferecer subsídios para a inserção das tecnologias no contexto educacional. Com esta perspectiva, o repositório permitirá ao professor maiores condições de escolha, definindo e encontrando recursos para transformar sua prática pedagógica, enriquecendo os ambientes de aprendizagem nas escolas brasileiras.

Em função disso, alunos e coordenadores da equipe da FCT/UNESP sentiram a necessidade de formar professores para o uso dessas mídias. As oficinas e os cursos de formação propiciaram aos docentes um contato mais estreito com o BIOE, explorando, analisando e conhecendo cada uma das suas funcionalidades. A partir desta iniciativa, muitos professores foram formados e passaram a utilizar os OE dentro do contexto escolar, articulando de forma significativa os recursos ao seus planos de aula.

No entanto, muitos outros profissionais ainda necessitam ser formados, da mesma forma, outras iniciativas, como as desta equipe, necessitam ser desenvolvidas com a finalidade de auxiliar os professores a implementar esses recursos no processo de ensino e aprendizagem de forma significativa.

Segundo Moran et.al. [18] é fundamental que o professor encontre estratégias mais adequadas para integrar as mídias em sala de aula. No entanto o professor só terá condições de criar diferentes estratégias se receber uma formação que valorize a construção do conhecimento e que proporcione uma reflexão sobre a prática pedagógica. O Ministério da Educação (MEC) ao longo dos anos criou diversos projetos com a finalidade de subsidiar a implementação das mídias no contexto escolar. Contudo nota-se que os currículos dos cursos de licenciatura e de pedagogia encontram-se defasados carecendo assim, de uma reestruturação.

Portanto, os OE e o repositório educacional do BIOE são ferramentas relevantes e que podem ser utilizadas no contexto escolar a fim de propiciar novas estratégias pedagógicas e novos conhecimentos ao aluno. Por sua vez, para que isso aconteça, é fundamental que o professor tenha uma formação inicial adequada, com o uso intensivo dos recursos tecnológicos, visando utilizá-los de forma a potencializar o processo de ensino e aprendizagem.

\section{Referências}

[1] J.M.Moran. Como utilizar as tecnologias na educação. Disponível em: < http://www.scielo.br/pdf/ci/v26n2/v26n2-5.pdf $>$ Acesso: 05 Março 2012

[2] J. A.Valente. (Org.). O computador na sociedade do conhecimento. In: J.A.Valente. (Org.). O computador na sociedade do conhecimento. Campinas: UNICAMP/NIED, 1999.

[3] N.L.Pretto; N,C,R.Riccio.A formação continuada de professores universitários e as tecnologias digitais Disponível em: $<$ http://www.scielo.br/pdf/er/n37/a10n37.pdf $>$ Acesso: 05 Março 2012

[4] P.A.A Rodrigues; M.I.R. Rodrigues. Banco Internacional de Objetos Educacionais (BIOE): Possibilitando o uso das Tecnologias na sala de aula.In: International Council for Educational Media (ICEM) and the International Symposium on Computers in Education (SIIE). 2011, Aveiro.Atas... Portugal. CD-ROM, arquivo: pdf. p.876-879.

[5] A.M.P.Carvalho.Uma metodologia de pesquisa para estudar os processos de ensino e aprendizagem em salas de aula.In:,F.M.T.Santos;I.M;A.Greca. A Pesquisa em Ensino de Ciências no Brasil e suas Metodologias.Ijuí:Ed.Unijuí,2007. 
[6] M.I.R.Rodrigues. Professores-pesquisadores: Reflexão e a mudança metodológica no ensino da Termodinâmica. São Paulo: USP, Instituto de Física e Faculdade de Educação, 2001a (Dissertação, Mestrado, 196p.)

[7] P. A .Perrenoud.Prática reflexiva no ofício do professor: Profissionalização e Razão Pedagógica. Porto Alegre: Artmed,2002.

[8] E.T.M.Schlünzen. Mudanças nas práticas pedagógicas do professor: criando um ambiente construcionista contextualizado e significativo para crianças com necessidades especiais físicas. São Paulo: Tese de Doutorado, PUC/SP, 2000.

[9] M. E. B.Almeida Educação Projetos Tecnologia e Conhecimento - $1^{\text {a }}$ ed. - São Paulo:

PROEM, 2001.

[10] J.C.Valente. A espiral da aprendizagem e as tecnologias de informação e comunicação:repensando conceitos. In: M. C. R. A.Joly (org). A tecnologia no ensino: implicações para a aprendizagem. São Paulo: Casa do Psicólogo, pp.15-37. 2002.

[11] Brasil. Ministério de Educação.Banco Internacional de Objetos Educacionais.2008.Disponível em: <http://objetoseducacionais2.mec.gov.br/> Acesso em:05 Março 2012

[12] L. M. R. Tarouco, M. C. Fabre, F. R. Tamusiunas. Reusabilidade de Objetos Educacionais. Disponível em: $<$ http://www.nuted.ufrgs.br/oficinas/criacao/mar ie_reusabilidade.pdf $>$ Acesso: 05 Março 2012

[13] F.S. Borba. Dicionário UNESP do português contemporâneo. São Paulo: UNESP, 2004.

[14] Brasil. Ministério de Educação a Distância. Normas para a Catalogação dos Recursos Educacionais Digitais: Repositório Internacional de Recursos Educacionais Digitais (Rired) e Portal do Professor. 2008.

[15] S. A de M. Arruda; C. E. Laburú. Considerações sobre a função do experimento no ensino de Ciências.In: NARDI, R. Questões atuais no Ensino de Ciências. São Paulo: Escrituras, 1998.

[16] M.C.L.Afonso; T.G. Eirão;J.H.M. Melo;,J.S. Assunção;S.V Leite. Banco Internacional de Objetos Educacionais (BIOE): tratamento da informação em um repositório educacional digi-
tal.2011.Disponívelem:<http://www.scielo.br/sci elo.php?script $=$ sci_arttext\&pid=S141399362011000300009\&lng=pt\&nrm=iso $>$ Aces so em: 05 Março 2012.

[17] P.A.A. Rodrigues. Pesquisa, seleção e catalogação de materiais digitais de física para o Banco Internacional de Objetos Educacionais (BIOE). São Paulo, 2009, 50 p. (Trabalho de Conclusão de Curso) CD-ROM.

[18] J.M.Moran; M.T. Masetto;M.A.Behrens. Novas Tecnologias e mediação pedagógica. Campinas SP: Papirus $2000.19^{\circ}$ edição. 